\title{
Impact of MOOCs on Regional Differences in Higher Education in China*
}

\author{
Cheng $\mathrm{Li}$ \\ Beijing Normal University, Zhuhai \\ Zhuhai, China 519087
}

\begin{abstract}
The rapid development of China's economy has brought about profound changes in higher education, which has moved from elitism to massification and even popularization. The field of higher education has always been the focus of all sectors of society. Under the influence of regional economic development level, natural geographical location and other factors, regional differences in the field of higher education are becoming increasingly prominent. As a new means of education technology, MOOCs also provide a new thinking mode for narrowing regional differences in education. Focusing on the field of higher education in China, through literature analysis, firstly, this paper clarifies the development process and mode of MOOCs; secondly, it sorts out the existing regional differences in Chinese higher education; finally, according to the characteristics of MOOCs, it discusses the promoting role of MOOCs in closing regional differences in China's higher education from four aspects, namely, economic perspective, open universities, high-quality educational resources and teacher cultivation, and criticizes them.
\end{abstract}

\section{Keywords-MOOCs; higher education; regional differences}

\section{INTRODUCTION}

MOOCs refer to online courses for open access and mass participation. (Massive Open Online Course, hereinafter referred to as MOOCs) In 2013, MOOCs made a big push into China. In January, The Chinese University of Hong Kong joined the Coursera platform. In April, Hong Kong University of Science and Technology joined Coursera. Six Asian universities, including Peking University, Tsinghua University, The University of Hong Kong and Hong Kong University of Science and Technology, joined edx on May 21. On July 8, Fudan University and Shanghai Jiaotong University also announced their participation in Coursera.

Tsinghua University held a mass online education BBS on June 3 Experts from nearly 30 universities including Tsinghua University, Peking University, Beijing Normal

*This paper is the research result of the 2015 University-level Scientific Research Project of "Strengthening the University Through Innovation" to improve the independent innovation ability (Project No.: 201571016); Research on Practical Teaching Reform of Media Product Production Courses from the Perspective of Media Convergence (Project No.: 2018310); 2018 Guangdong Education Science "13th Five-year Plan" moral education special research project (Project No.: 2018JKDY04) and the 2018 Research Capacity Improvement Program of Beijing Normal University, Zhuhai (Project No.: 201850014).
University and Fudan University attended BBS. Tsinghua University has carried out a lot of work on online education. It has established the Tsinghua University Research Center on Large-scale Online Education to make in-depth study of the laws of teaching and learning, promote the integration of advanced computing and network technology with education, and improve the quality and efficiency of students' learning.

On July 9, Shanghai Jiaotong University held The International Forum on Online Education Development. Leaders of the Ministry of Education, Shanghai Municipal Education Commission, the global online education alliance, Coursera, experts and scholars from more than 10 universities in China and abroad, and business people, a total of over 200 people attended the conference. A consensus has been made among the C9 universities and some 985 universities that with the support of the ministry of education, they will discuss how to build MOOCs in China, establish several high-level online course platforms, realize the sharing of high-quality online courses, and promote the reform of teaching mode in Chinese universities.

In addition to the positive regard for MOOCs from universities, some Chinese companies are following suit, launching a series of initiatives to get ahead of the curve. NetEase, Sina, Guokr.com and others have launched open online courses.

Youku has reached an exclusive official cooperation with Udacity, becoming the first and only channel platform for Udacity course release in China. Youku education channel has launched the latest nearly 1,000 episodes of online video courses of Udacity including translated into Chinese, including Introduction to Statistics, Introduction to Entrepreneurship and Introduction to Computer that have been translated to Chinese.

MOOCs are booming in China thanks to the Chinese government's emphasis on them, essentially on education as a whole. The Chinese government has always put education in a very prominent position. The report to the 18th national congress made clear the importance of education - the cornerstone of national rejuvenation and social progress. The twelfth five-year plan for the development of national education points out, "... In accordance with the policy of 'giving top priority to development, education, reform and innovation, promoting fairness and improving quality', we should take education as the fundamental requirement, 
promoting fairness and improving quality as the key task, reform and innovation as the driving force, and giving top priority to development as the guarantee..." (Ministry of Education of the People's Republic of China, 2012) The document emphasizes the priority to develop education and build a country rich in human resource through education. To achieve this goal, attention must be paid to educational equity and equal educational opportunities (equal access to education). Efforts should be made to promote equity and justice in education, strive to promote balanced education, pay attention to the right to education of different regions, urban and rural areas, and disadvantaged groups, and ensure that everyone has the opportunity to enjoy education, which is an urgent need for China's social and economic development.

MOOCs have been closely related to higher education since birth. The world's first MOOC was a college course. Therefore, this paper will focus on the field of higher education in China. Through literature analysis, it will first clarify the development process, mode and characteristics of MOOCs. Secondly, the existing regional differences in Chinese higher education are sorted out. Finally, the paper proposes and criticizes the role of MOOCs in promoting regional differences in China's higher education.

\section{OVERVIEW OF MOOCS}

The rapid development of science and technology is constantly changing the form of education. Thinking about the blackboard invented in 1841, radio in 1910, film in 1940, television in 1957 and computer in 1967, it can be found that every technological advance brought new changes to education. Since 2000, experts and scholars have conducted various researches on how the Internet and information technology will revolutionize the forms and methods of education. MOOCs are emerging on the basis of the increasingly mature Internet and information technology. Education technology is not new. Before MOOCs, correspondence education, online education and distance education were all popular at a time, but these technologies eventually became an auxiliary tool for education, without shaking the fundamental system of higher education. So what exactly is MOOCs? Why can it arouse social concern from the very beginning? How has MOOCs evolved and changed? What characteristics does MOOCs have?

\section{A. Definition and Development History of MOOCs}

MOOCs are actually the product of the combination of the connectionism and practice of online learning. Professor Stephen Downes, internationally renowned education scholar and co-founder of connectionism and MOOCs, told the journal, "... As far as I am concerned, the theory of connectionism is learning network, which means that learning is regarded as the formation process of network...Since information exists in each node of the learning network in the form of distributed knowledge representation, we need to connect these nodes with a certain structure, and form new knowledge through continuous refinement, reconstruction and interpretation, so as to build a technology-enhanced learning network in which people share content. In my opinion, the theory of connectionism originates from the knowledge philosophy of associationism and is rooted in the connectionism theory of artificial intelligence (connectionism) (Hu Yilin, Hu Xiaoqing, 2013). In 2004, Professor George Siemens, another founder of MOOCs, also gave an article about connectivism "Connectivism: A Learning Theory for the Digital Age" (George Siemens, 2004). It points out, "...technology has reorganized how we live, how we communicate, and how we learn." In the Internet age, learning is no longer an individual process, nor does knowledge stay in the classroom and books. It exists everywhere around us. A website, a library and even a book are all just nodes of knowledge. Through a certain structure, this scattered knowledge can be united and reorganized into new network connections to help learners learn.

How can this idea be reflected in practical learning? In the fall of 2008, Downes and Siemens launched a Mooc Connectivism and Connective Knowledge (CCK08) at the university of Manitoba, which attracted nearly 2,200 students (Hu Yilin and $\mathrm{Gu}$ Xiaoqing, 2013). The learning channel of this course is the Internet, but it is not a single Internet, but a convergent one: The teachers and students have built 170 blogs and integrated them through ss2 (rich website summary) to make the website, discussion group and BBS serve learners together.

In 2011, Professor Sebastian Thrun of Stanford University and his colleagues opened the course "Introduction to Artificial Intelligence" to the world, attracting 160,000 learners from more than 190 countries, and 23,000 people finally completed the course (Metz, 2013). MOOCs have officially entered the public's vision, which has ignited the enthusiasm of education circles, media and investors.

The Massachusetts Institute of Technology and Harvard University have co-founded edx, a non-profit open source platform. So far, edx offers 175 online courses and has 48 university partners - all world-class universities, including Harvard University, MIT, University of California, Berkeley, University of Queensland, Peking University and Tsinghua University (edX, 2014).

In 2012, Andrew Ng, a professor of computer science at Stanford University, founded the for-profit Coursera, with early partnerships including Stanford, the University of Michigan, Princeton and the University of Pennsylvania. By July 2019, Coursera had 3,626 online courses to choose from and 190 partners from 43 countries and regions around the world (Coursera, 2019).

Subsequently, more and more institutions have entered the field of MOOCs, such as Udemy and P2PU. Sir John Daniel thinks that, "MOOCs are the educational buzzword of 2012" (Sir Daniel, 2012). New York Times reporter Laura Pappano also wrote "The Year of the MOOC" in her article (Pappano, 2012). 


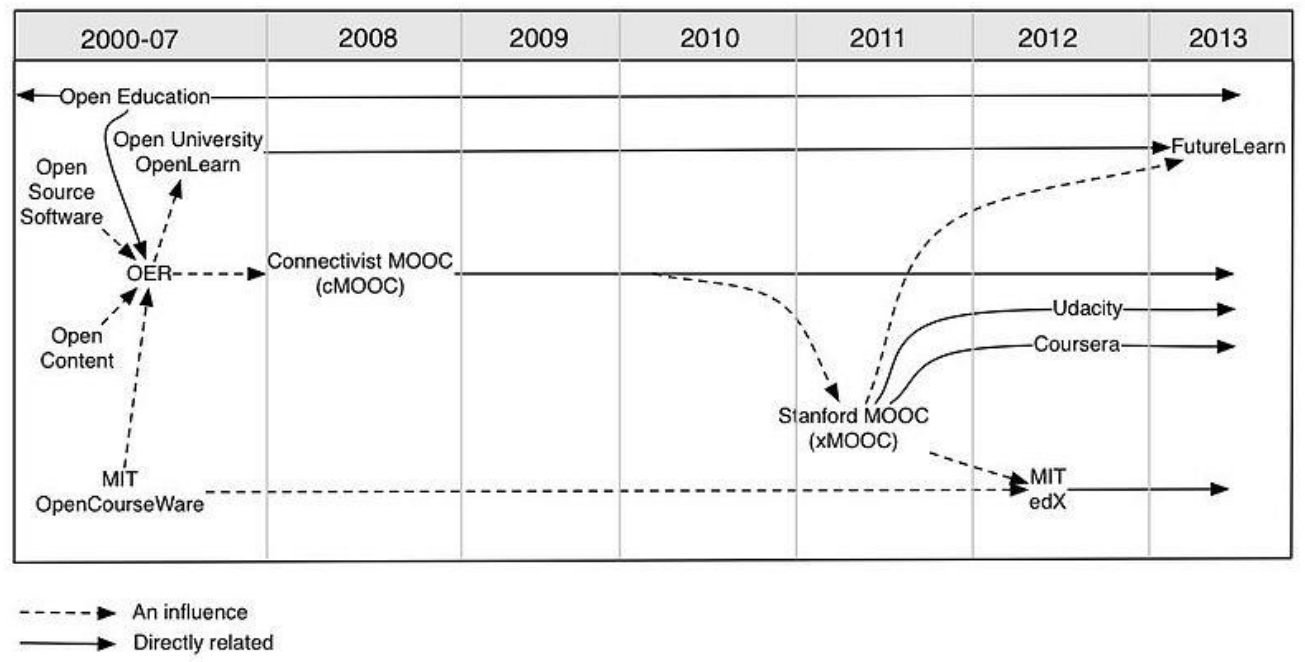

Fig. 1. Development of MOOCs providers.

a. Data source: Li Yuan and Stephen Powell. JISC CETIS (2013). MOOCs and Open Education: Implications for Higher Education. Retrieved from http://publications.cetis.ac.uk/2013/667

The overall development of MOOCs can be shown in "Fig. 1".

\section{B. The Characteristics of MOOCs}

After several years of development, the types and patterns of MOOCs have taken shape. Both professor Downes and Sir Daniel divide them into two categories: cMOOCs and xMOOCs. Based on the connectivism theory of professor Downes, cMOOCs makes learning a process of finding resources on the Internet and linking them to courses (Hu Yiling, Gu Xiaoqing, 2013). Great differences as there are whether in teaching philosophy, learning process, or teaching methods, etc., now the public is used to using the same term, MOOCs to refer to them. This paper focuses on the discussion of xMOOCs, because compared with cMOOCs it attracts more attention, involves more schools and institutions, affects a wider range of learners, and thus generates richer data.

To explore the characteristics of MOOCs and trace its origin, it is important to start from the origin of its name, which reflects its essence and connotation. MOOCs stands for Massive Open Online Course (MOOCs), which means Massive Open Online Courses, and "Massive", "Open" and "Online" are its three major characteristics.

"Massive" means the scale of students is Massive and the amount of data that's generated is Massive. As mentioned above, the course "Introduction to Artificial Intelligence" of Thrun professor from Stanford University has attracted 160,000 learners, which is unimaginable in traditional college education.

"Open" means that learning resources are open to all. For professor Downes, open learning resources also mean free of charge, that is, free access ( $\mathrm{Hu}$ Yiling and $\mathrm{Gu}$ Xiaoqing, 2013). Not only are MOOCs open to everyone, they are also free (though many MOOCs institutions now charge learners a small fee to recognize credits or certifications). Meanwhile, the openness of MOOCs is also reflected in the freedom of learning. MOOCs are asynchronous approaches that do not require learners to be in the same place at the same time. Learners can freely choose the time and place to watch the video, or even choose not to watch part of it, and can formulate personalized learning methods based on their own actual conditions.

"Online" means that the whole learning process, from teaching to learning, is done over the Internet. In theory, as long as a learner has a computer that can be connected to the Internet, he or she can learn online, and that learning can be interactive. On the Internet, learners can carry out various discussions with teachers and classmates. All kinds of MOOCs educational institutions will set up special areas for learners to communicate with each other.

\section{REGIONAL DIFFERENCES IN CHINESE HIGHER EDUCATION}

The "Outline of the National Program for Medium- and Long-term Education Reform and Development (20102020)" (2010) explicitly mentions "... To meet the needs of national and regional economic and social development, a dynamic adjustment mechanism should be established to constantly optimize the structure of higher education... and optimize the regional layout structure. It is necessary to set up special funds to support local higher education, and implement the plan to revitalize higher education in the central and western regions. The new enrollment plan should be geared toward areas in the central and western regions where higher education resources are in short supply. Efforts should be made to expand the enrollment of eastern universities in the central and western regions, and increase support for their counterparts in the western regions." It can be seen that regional differences in higher education have been existing and have a profound impact on the relevant government decisions. The regional differences in higher 
education are mainly reflected in three aspects: the scale of education, teachers and educational funds.

\section{A. Scale of Education}

The scale of regional higher education mainly includes the number of universities and the number of college students. According to "China Statistical Report 2018" and Main Data of the Sixth National Census in 2010" (2011) and other relevant data, the distribution of higher education in China is uneven. In terms of the total number of regular institutions of higher learning, there are 2,631 general institutions of higher learning in China, among which Jiangsu (167), Guangdong (151) and Shandong (145) have the largest share. The three provinces with the smallest share are Tibet (7), Qinghai (12) and Ningxia (19). In terms of the number of college students, the top three are Shandong (571, 220), Guangdong $(511,222)$ and Henan $(504,119)$. The three least populated provinces are Tibet $(9,020)$, Qinghai $(14,661)$ and Ningxia $(31,563)$. The eastern and southern regions are far ahead of the western and northern regions.
As shown in "Fig. 2", in terms of the gross enrollment rate of higher education, the eastern region is much higher than the central and western regions, and the northeast region is higher than the national level of $26.9 \%$. Among them, the gross enrollment rate of higher education in Shanghai, Beijing and Tianjin all reaches above $60 \%$. According to the American sociologist Trow Martin about the theory of higher education, if the gross enrollment rate of a country's schoolage youth into higher education does not reach $15 \%$, it is in an elitist period of higher education; if it exceeds $15 \%$ to $50 \%$, it is in the massification period of higher education; and, if it exceeds $50 \%$, it is in the popularization period of higher education. According to this theory, Shanghai, Beijing and Tianjin have entered the stage of popularization of higher education, while other regions are still in the stage of massification of higher education. Therefore, in terms of the scale of higher education, there are huge differences between the eastern and western regions. China's highquality education resources are mainly concentrated in the eastern regions, and the educational development level of the western regions is still in a disadvantaged position.

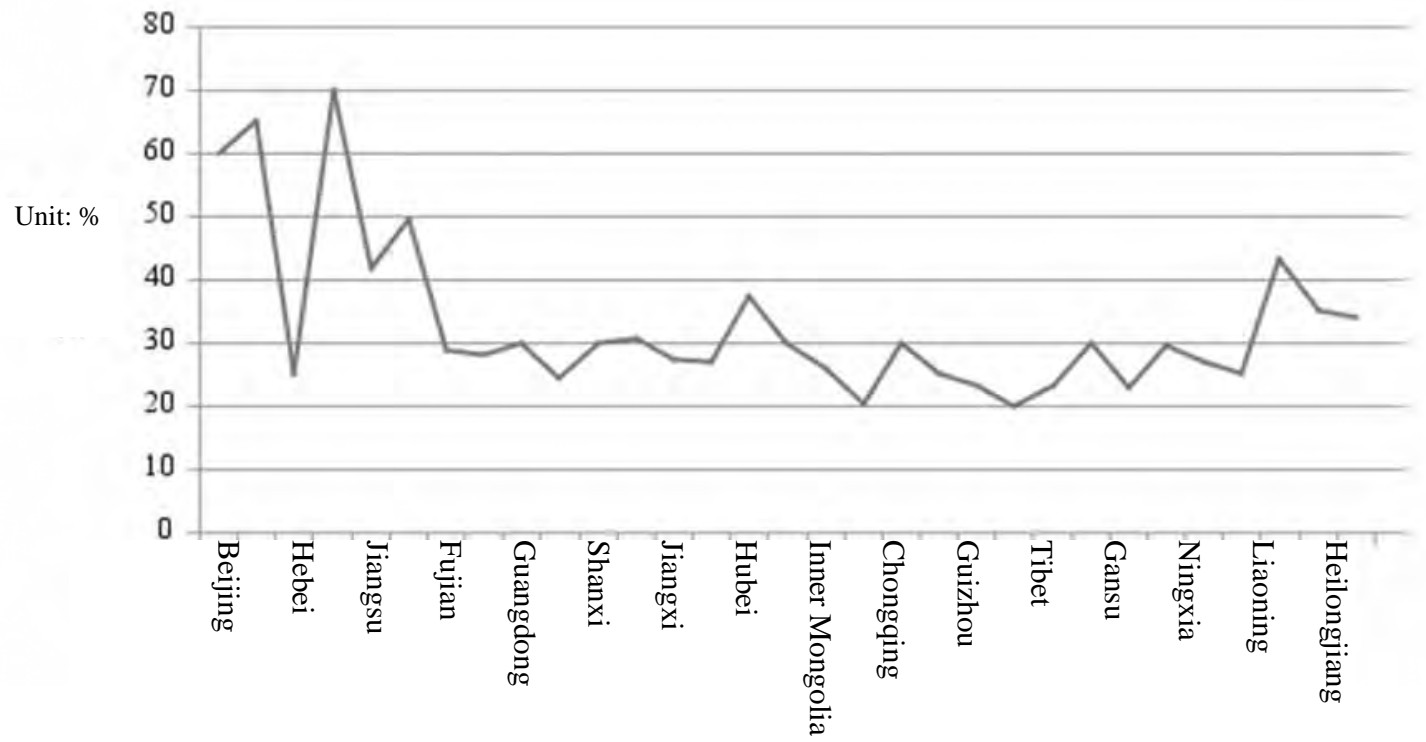

Fig. 2. Gross enrollment rate of higher education in various regions of China in 2011.

\section{B. Teachers}

The main indicators to measure the teacher resources in regional colleges and universities include the number of staff and teachers, the number of full-time teachers, and the number of deputy senior teachers or above. According to the "China Statistical Yearbook 2012", the eastern region was significantly higher than other regions in these numbers, with Jiangsu, Shandong, Guangdong and other eastern provinces ranking high, while the western region ranked the lowest. In addition, 39.81 percent of China's full-time teachers have intermediate and senior professional titles, and the proportion in the eastern and northeastern regions is higher than the national level, while the proportion in the central and western regions is lower than the national level. It can be seen that the eastern region has the most advantages in terms of teachers, followed by the northeast. Although Qinghai and other cities are in good condition, the overall level of the western region is not good.

\section{Educational Funds}

According to the "China Educational Finance Statistical Yearbook 2012" (2013), there is a significant gap in educational expenditure among regions in China. The data of 2011 shows that, Beijing ranked first with 76,586,700 yuan, followed by Jiangsu (51,826,900 yuan), Guangdong $(42,076,400$ yuan), Shanghai $(390,774,200$ yuan) and Shandong (36,302,900 yuan). The top five are all in the eastern region, and the level of educational investment in the 
western region lags far behind the developed eastern provinces. Taking Beijing at the top of the ranking and Tibet at the bottom of the ranking as an example, the total amount of higher education funds in Beijing is about 65 times that in Tibet, which shows the gap between the investment of higher education funds in the east and the west. From the educational expenditure per student in higher education, it can be seen that Beijing $(65,806.78$ yuan) and Shanghai $(48,807.71$ yuan) still ranked first and second, ahead of other provinces and cities.

On the basis of studying the above indexes of higher education, the author holds that there are significant differences among regions of higher education in China. These differences are influenced and restricted by many factors, such as regional economic development level, natural geographical location, resource factors, policy factors, cultural traditions and other factors, which will form regional differences in higher education.

\section{MOOCS ARE A TOOL TO NARROW REGIONAL DIFFERENCES IN CHINA'S HIGHER EDUCATION}

The balanced development of education is the core problem that needs to be solved urgently to realize the healthy development of education and social equity and justice in China. At present, promoting educational equality through various information technology means has become an important policy repeatedly emphasized by senior decision-makers.

\section{A. Information Technology Can Narrow Regional Gaps in China's Higher Education}

Although the "Outline of the national program for medium- and long-term education reform and development (2010-2020)" (2010) does not explicitly link information technology with education equity, it proposes the expressions like "to give full play to the role of modern information technology so as to promote sharing of quality teaching resources", "to focus on strengthening the information infrastructure construction of rural schools so as to narrow the digital gap between urban and rural areas", "to establish an open and flexible public service platform for educational resources and promote the popularization and sharing of high-quality educational resources... to continue to promote distance education for primary and secondary schools in rural areas, so that teachers and students in rural and remote areas can enjoy high-quality educational resources", etc. In essence, the logic behind these similar statements also emphasizes the sharing of high-quality educational resources through information technology, thus promoting the fair and balanced development of education.

With the development of China's economy, the investment in education has increased significantly, and the conditions for running schools have been greatly improved. However, China's education development is still facing the severe form of regional differences in education. The unbalanced distribution of educational resources affects educational equity and becomes one of the main problems restricting the current educational development. The continuous development of information technology contributes to the increasingly in-depth integration of various technologies and education. What can information technology bring to education? Undoubtedly, it has become an established policy to narrow regional differences in education through information technology, which is widely accepted by the government and scholars. A more fundamental question is, can information technology really narrow the regional differences in higher education and achieve balanced development of education?

\section{B. MOOCs Have a Positive Role in Closing Regional Differences in Higher Education}

Taking MOOCs as an example, it is not only the application of new technology and means in the field of education, but also brings new ideas to our educational concept. As mentioned above, MOOCs can provide low-cost, long-distance, and more flexible access to specialized courses that were previously open to just an elite few on university campuses. This reduces the influence of college education scale, educatees' family economic status and other factors on learners. The characteristics of online learning break the regional limitations and make it possible to achieve a balanced education. This paper attempts to discuss the promoting role of MOOCs in narrowing regional differences in higher education from the perspective of economy, the concept of openness, high-quality learning resources and the cultivation of teachers.

1) Economic perspective: If the hardware cost of MOOCs learning is not taken into account, the learning cost is very low. Many of today's MOOCs offer courses that are free - whether they're from Harvard or MIT. It is attractive for learners to be able to study at a high level without having to pay for the study, or even having to pay for extra transportation. The rising cost of university tuition has put off many students. In the United States, where the average cost of a bachelor's degree is more than $\$ 100,000$, the cost of higher education has risen 360 percent since inflation began in 1986 (Archibald and Feldman, 2010). In his inaugural address, David ruff, the new President of Yale University, said, "The challenge of financial imbalance has been with colleges and universities of our kind for some time. Today, the fiscal challenge reaches a critical moment." But "new educational technologies have the potential to enable more individuals to learn the highest level of skills and knowledge at minimal cost." (2012). Because learning through MOOCs is free, students pay an additional fee (about $\$ 150$ per course) if they need to earn credits from certain courses recognized by the relevant university. Georgia tech is offering students a \$7,000 master's degree in udacity (Metz, 2013). MOOCs may reduce the huge cost of higher education. The low cost of learning provides an opportunity for more learners in economically underdeveloped or underdeveloped regions to study and give them a chance to enter "university". In fact, a large proportion of MOOCs learners come from underdeveloped or underdeveloped regions. Regalado mentioned this in an 
article in 2012, "Even though only a small fraction of those will actually complete a class, the rise of the MOOCs means we can begin thinking about how free, top-quality education could change the world. Khan's videos are popular in India, and the MOOC purveyors have found that 60 percent of their sign-ups are self-starters from knowledge-hungry nations like Brazil and China."

2) The concept of openness:The openness of MOOCs is at its core. On the one hand, it makes use of the Internet technology to make the free transmission of course information become a reality, which is not subject to the constraints of time and the geographical intervals are broken. Learners can take advantage of MOOCs to learn courses from world-class universities even in remote areas. MOOCs, on the other hand, have no requirements for learners. They don't have any requirements for learners (such as exams), age, gender, physical condition, etc. Taking China as an example, the biggest obstacle in the learning process for learners in many remote areas comes from geographical barriers, especially for those in western regions and northern regions. MOOCs are a big help for such learners, who can get a higher education without leaving their homes.

3) High-quality educational resources: Good teachers are an important part of a good university. For students who want to receive higher education, excellent schools and teachers are important pointers to choose a school, but only a few people have the opportunity to enter a first-class university and enjoy the guidance of excellent teachers. The core of modern information technology is the low-cost expansion of knowledge and innovation. MOOCs has minimized the human cost, time cost, space cost, transportation cost and a series of other costs, so that the scarce resources can be allocated in a wider range and with a higher allocation efficiency, and knowledge and information can flow, spread and popularize rapidly in a low-cost and efficient way. Therefore, today's public can have access to the high-quality education resources that were previously only available to a few nobles or elites, narrowing the distance between the public and the elites (Wang Mei, Xu Guangtao, Ren Youqun, 2014). In ancient times, only emperors or nobles could employ the most famous scholars as their teachers. The famous educator Confucius had only 3,000 disciples. But today's students can listen to world-class economists, historians, and physicists through MOOCs, and a single course can attract thousands, if not tens of thousands, of learners. For economically underdeveloped regions, MOOCs means using the Internet to promote the redistribution of excellent educational resources and narrow the gap of education level with developed regions. A survey by the Institute of Education Tsinghua University proves this point, pointing out that less than 40 percent of the 91 respondents came from universities in the "985" and "211" projects, based on the types of schools they attended. It is worth noting that students from other undergraduate colleges have the highest enthusiasm for MOOCs learning, accounting for more than half of the effective applicants, and a very few (2) are from higher vocational colleges. As far as the actual situation is concerned, the number of students from universities in the "985" and "211" projects with relatively rich teaching resources who use MOOCs for learning is relatively small. Even though the proportion of MOOCs learners in "985" and "211" universities may be higher than that in other undergraduate universities, the number of students participating in MOOCs is still larger than that in other undergraduate universities. (Liu Yang, Huang Zhenzhong, Zhang Yu, Li Manli, 2013)

4) Cultivation of teachers: There are also teachers who learn through MOOCs. The survey made by the Institute of Education Tsinghua University also shows this, "Of the nine teachers who answered this question, six came from colleges and universities, three from the general education level, and none from the preschool level. College and university teachers account for two-thirds of the total, so it can be seen that there is a strong demand for them to get new research progress from MOOCs to update their teaching content. From the perspective of teachers' teaching, MOOCs can also promote the sharing of high-quality educational resources and improve the teaching quality of colleges and universities, and thus improve the learning experience of college students." (Liu Yang et al., 2013)

\section{CONCLUSION}

To sum up, MOOCs, a new thing developed by virtue of Internet technology, plays a positive role in closing regional differences in China's higher education from the perspective of economy, open universities, high-quality educational resources and teacher cultivation.

At the same time, since information technology usually brings high expectations, even educational technology researchers admit that "during the history of educational technology development, educational technology researchers have made greater promises than they actually have" (Merrill and Elen, 2014). What problems should arouse people's vigilance in the process of practice? How to better realize the original intention of using information technology like MOOCs to really narrow regional differences in higher education?

Firstly, according to Sir Daniel, one of the paradoxes of MOOCs is that most educational institutions of MOOCs only provide certificates to students who successfully pass the course examination without giving credits (Daniel, 2012). That is to say, the results obtained through MOOCs cannot be effectively certified. If the supporting credit policy and online education quality assurance policy can be gradually developed and improved in the future, it is believed that MOOCs will provide more ideas for the settlement of regional differences in higher education.

Second, the completion rate of MOOCs is generally low. According to the data provided by Sir Daniel, the learner completion rate of MOOCs educational institutions is only 
$10 \%$ or less (Daniel,2012), which means that it is difficult for individuals to complete their studies independently. If MOOCs is used to narrow the regional gap in higher education, it becomes is an unavoidable problem how to help learners to complete the course smoothly, so that the completion rate reaches a relatively high level.

Finally, mastering information technology is only the first step in the Internet age. What students from economically underdeveloped regions and disadvantaged groups do with information technology after they master it, and whether there are differences between them and students from economically developed regions in the use of information technology, is the new focus of governments of various countries when they use information technology to promote education equity policy. On the one hand, information technology can narrow regional differences in education. On the other hand, information technology exacerbates regional disparities in education, leading to the "digital divide" (the gap in the ownership and use of modern information technology between different social groups) between the "information-rich" and the "information-poor". Will the use of MOOCs to reduce regional differences in education eventually lead to a widening of the gap? Of course, it needs to be pointed out that the source of the "digital divide" is not information technology, but the replication and reproduction of the original social inequality and educational inequality in the information age and network society.

\section{REFERENCES}

[1] MOOCs College. May 20, 2014. Retrieved from http://MOOCs.guokr.com/opinion/. (in Chinese)

[2] Wang Mei, Xu Guangtao, Ren Youqun. Promoting Equity in Education Through ICT: A Double Edged Sword? Global Education. 2014: 2, 39-48. (in Chinese)

[3] Central Committee of the Communist Party of China (2013). Decisions of the CPC central committee on several major issues concerning comprehensively deepening reform. Retrieved from http://www.sn.xinhuanet.com/2013-11/16/c 118166672.htm (in Chinese)

[4] Ministry of Education of the People's Republic of China. The twelfth five-year plan for the development of national education, 2012. Retrieved from http://www.moe.gov.cn/publicfiles/business/htmlfiles/moe/s6855/201 207/xxgk_139702.html. (in Chinese)

[5] Ministry of Education of the People's Republic of China. Outline of the national program for medium- and long-term education reform and development (2010-2020), 2010 Retrieved from http://www.edu.cn/zong_he_870/20100730/t20100730_501910.shtml. (in Chinese)

[6] National Bureau of Statistics. China Statistical Yearbook 2012 Beijing: China Statistics Press, 2012. (in Chinese)

[7] The Sixth National Census Office of the State Council of the People's Republic of China, population and employment statistics department of the national bureau of statistics. Data from the sixth national census in 2010. Beijing: China Statistics Press, 2011. (in Chinese)

[8] National Bureau of Statistics, Department of Finance, Ministry of Education of the People's Republic of China, Statistics Department of Social Science, Technology and Cultural Industry (2013). China Educational Finance Statistical Yearbook 2012. Beijing: China Statistics Press, 2013. (in Chinese)
[9] Li Ling. On the development strategy of regional higher education in China. Journal of Higher Education, 1994, 04. (in Chinese)

[10] Premier $\mathrm{Li}$ stressed the importance of fairness in education and promoting scientific and technological innovation. 2014. Retrieved from http:// news. Xinhua. With bipolar -08/31/c_117173898. Htm. (in Chinese)

[11] Wu Yan. The Following 100 Years. Oriental Morning Post, b11. December 28, 2012. (in Chinese)

[12] Hu Yiling, Gu Xiaoqing. From Connectivism to MOOCs: Connecting Knowledge \& Sharing Resources - An Interview with Stephen Downes Open Education Research, 2013: 19 (6), 4-10. (in Chinese)

[13] Yuan Li, Stephen Powell, Ma Hongliang. An analysis of the international status of MOOCs. Open Education Research, 2013: 19 (3), 56-62. (in Chinese)

[14] Zhao Qingnian. Division and Cooperation: Real Demand and Rational Appeal of Local Higher Education's Coordinate Development. Heilongjiang Researches on Higher Education. 2009: 1, 13 to 17. (in Chinese)

[15] Zhao Ke, Wang Jinzhan trans. Higher education is about to embark on a great experiment (Reil). Research On Education Tsinghua University. 2012: 33 (6), 1 to 5. (in Chinese)

[16] Liu Yang, Huang Zhenzhong, Zhang Yu, Li Manli. A Report on MOOCs Participation in China. Research On Education Tsinghua University. 2013: 34(4), 27-35. (in Chinese)

[17] Yan Quanzhi. An empirical study on regional higher education and unbalanced economic development. Research in Education Development, 2006: 23, 62-65. (in Chinese)

[18] Archibald, R. B. \& Feldman, D. H. Why Dose College Cost So Much? USA: Oxford University Press, 2010

[19] Baggaley, J. (2011). Harmonizing Global Education: From Genghis Khan to Facebook. London and New York: Routledge.

[20] Bates, A. W. \& Sangra, A. Managing Technology in Highe Education: Strategies for Transforming Teaching and Learning. San Francisco: Jossey Bass, 2011

[21] Coursera. 2019. Retrieved from https://www.coursera.org

[22] edX. 2014. Retrieved from https://www.edx.org

[23] George Siemens. Connectivism: A Learning Theory for the Digital Age. $2004 . \quad$ Retrieved from http://www.elearnspace.org/Articles/connectivism.htm.

[24] Harden N. The end of the university as we know it. The American Interest. December 11, 2012. Retrieved from http://www.theamerican-interest.corn/article.cfm?piece $=1352$.

[25] Laura Pappano. The Year of the MOOC. NY Times, November 2 $2012 . \quad$ Retrieved from http://www.nytimes.com/2012/11/04/education/edlife/massive-openonline-courses-are-multiplying-at-a-rapid-pace.html?pagewanted=all.

[26] Li Yuan and Stephen Powell. JISC CETIS. MOOCs and Open Education: Implications for Higher Education, 2013. Retrieved from http://publications.cetis.ac.uk/2013/667

[27] Merrill, M. D. \& Elen, J. A look forward, 2014. In J. M. Spector, M D. Merrill, J. Elen, \& M. J. Bishop (Eds.), Handbook of research on educational communications and technology (4th Edition) (pp. 873874) . New York, NY: Springer Science + Business Media.

[28] Metz, R. Sebastian Thrun on the Future of Learning. 2013, July 19 Retrieved from http://www.technologyreview.com/news/517181/sebastian-thrun-onthe-future-of-learning/

[29] Regalado, A. The Most Important Education Technology in 200 Years, 2012. Retrieved from: http://www.technologyreview.com/news/506351/the-most-importanteducation-technology-in-200-years/

[30] Sir Daniel, J. Making Sense of MOOCs: Musings in a Maze of Myth, Paradox and Possibility. Journal of Interactive Media in Education, 2012. Retrieved from http://jime.open.ac.uk/article/2012-18/html

[31] Touve. D. MOOCs' Contradictions, 2012. Retrieved from http://www.insidehighered.com/views/2012/09/11/essay- 
contradiction-facing-MOOCs-and-their-university-

sponsors\#sthash.0WWyPCAA.dpbs

[32] Udacity. 2014. Retrieved from https://www.udacity.com 